\title{
A WIDERÖE-BASED HEAVY ION PREACCELERATOR FOR THE SUPERHILAC
}

John W. Staples, Henry D. Lancaster and Roland B. Yourd

March 1979

Prepared for the U. S. Department of Energy under Contract W-7405-ENG-48

\section{TWO-WEEK LOAN COPY}

This is a Library Círculating Copy which may be borrowed for two weeks.

For a personal retention copy, call Tech. Info. Dívision, Ext. 6782

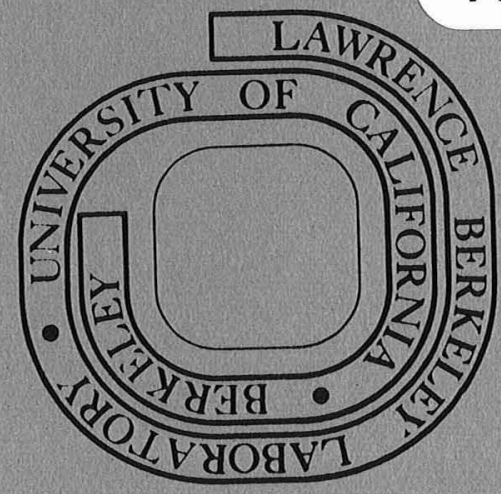

\author{
RECEIVED \\ LAVRENCE \\ BERKELEY LABORATORY \\ MAY 81979 \\ LIBRARY AND \\ DOCUMENTS SECTION
}




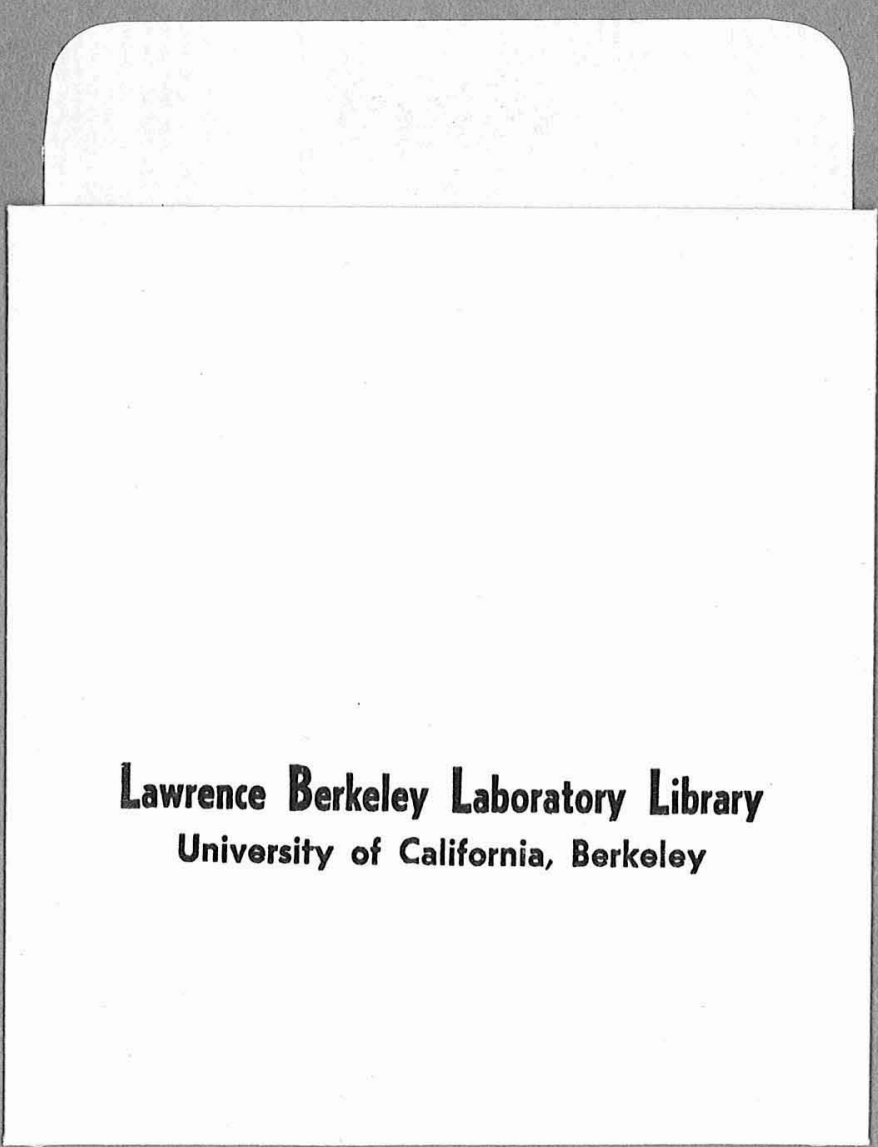




\section{Abstract}

A new high-mass, high intensity injector for the SuperHILAC has been approved and is under construction at LBL. A high power intermediate charge state ion source and accompanying low-velocity linac will provide beams for subsequent acceleration by the SuperHILAC: Both axially and radially extracted ion sources will be accommodated and charge state analyzed in the $750 \mathrm{kV}, 100 \mathrm{kHz}$.Cockcroft-Walton terminal. The LEBT will provide isotopic analysis to 1 part in 300. A $5 \mathrm{~m}$ long, $23.4 \mathrm{MHz}$ Wideröe linac, operating in the $\pi-3 \pi$ mode based on the GSI design accelerates typically a $\mathrm{U}^{+5}$ ion to $113 \mathrm{keV} / \mathrm{a}$ where it is stripped to $\mathrm{U}^{+11}$ by a perfluoropolyether vapor stripper and further accelerated by the SuperHILAC. The space charge limit of the system is several electrical $\mathrm{mA}$ which will be approached in the intermediate mass range.

\section{Introduction}

A low-velocity, high current Wideröe linear accelerator is under construction at LBL. This accelerator system, including a new ion source and pre-injector, will serve as an injector to the SuperHILAC, supplementing two presently operating injectors, increasing the mass range to uranium and increasing the flux for ion species higher than argon up.

As the basic parameters of this injector have been covered in a previous paper ${ }^{1}$ we will emphasize the highlights of this design, particularly those items of novel or unique interest that have already been built and tested individually.

The basic parameters of the injector have remained essentially constant except for the selection of charge state of the design ion, uranium, and the selection of the maximum terminal potential of the Cockcroft-Walton preaccelerator. The design charge state has been adjusted downward to $\mathrm{U}^{5+}$ to provide a larger available flux of ions. This means that Ar ${ }^{1+}$ will also be available, allowing us to experiment with the effects of accelerating large currents through the machine, near its space charge limit of approximately $10 \mathrm{emA}$. The preaccelerator voltage has been raised to $750 \mathrm{kV}$ to accommodate the reduction in charge state of the accelerated ion.

The Wideröe linac increases the kinetic energy of the accelerated ion from $15.8 \mathrm{keV} / \mathrm{amu}$ to $113 \mathrm{keV} / \mathrm{amu}$ for injection into the first tank of the

*This work was supported by the High Energy \& Nuclear Physics Division of the U.S. Department of Energy under contract No. W-7705-ENG-48

**Lawrence Berkeley Laboratory

1 Cyclotron Rd.

Berkeley, California 94720

1. J. Staples et. al, A Wideröe Pre-Accelerator for the SuperHILAC, 1976 proton Linear Accelerator Conference, P. 81.
SuperHILAC, After the Wideröe, the beam is stripped in a Fomblin vapor stripper: The stripping efficiency into a single charge state has been measured at $11 \%$ for $\mathrm{Pb}$, rising to $17 \%$ for $\mathrm{Xe}$.

\section{Preinjector System Summary}

The preinjector consists of a $750 \mathrm{kV}$ highfrequency Cockcroft-Walton stack containing two ion sources in the terminal. An axial source of the Ehlers type is provided for the nobel gases and a sputter-arc radially extracted PIG for the metallic Ions. $90 \mathrm{kVA}$ of power is available in the terminal through a rotating shaft drive. A $150 \mathrm{hp},, 1,800$ rpm motor will be located in a pit in the floor beneath the terminal house and a vertical 10" OD by 0.5 " wall filament wound epoxy tube drive shaft will transmit the power to two generators in the high voltage terminal: a $65 \mathrm{KVA} 60 \mathrm{~Hz}$ unit and a $25 \mathrm{KVA} 400 \mathrm{~Hz}$ unit. Cryogenic pumping will be used near the ion sources to recover rare and expensive source gases and to reduce the power and weight requirements. Terminal cooling will be by means of Freon-113 circulated from the ground end to high voltage through 2-1/2" diameter insulating plastic tubes (nylon or delrin) at a flow rate of $40 \mathrm{gpm}$.

The accelerating column will consist of three $30 \mathrm{~cm}$ long sections of commercially available titanium-ceramic modules in an atmosphere of $\mathrm{SF}_{6}$. Uniform grading is used, and the current limit is $15 \mathrm{emA}$ at $750 \mathrm{kV}$. In the $60 \mathrm{~cm}$ space between the source analyzing magnet and the column entrance a series of magnetic quadrupoles focuses and matches the beam. The very short cell length reduces the maximum tune depression to less than 0.5 For the maximum uncompensated space charge.

The LEBT between the column exit and Wideröe entrance contains four sets of doublets, steering, a $90^{\circ}$ analyzing magnet and one fundamental frequency buncher of the quarter-wave line type. For low to moderate current, the analyzer will provide an isotopic mass analysis of one part in 300 , allowing us to use natural source material for all but the most intense beam requirements.

\section{IIa. Axial Ion Source}

For ions from gaseous source material, we will use an axially-extracted source similar to those developed at LBL by Ehlers ${ }^{2}$ for neutral beam injection and reported on elsewhere in this conference 3 . We have accelerated $60 \mathrm{emA}$ of $\mathrm{Xe}^{1+}$ from a version of this source to $475 \mathrm{keV}$ and in another series of runs have shown that we can expect about $10 \%$ of the total beam output to be $\mathrm{Xe}^{3+}$. This source shows a noise modulation of 0 to $10 \%$.

\section{IIb. Cockeroft-Walton}

The CW power supply will be a half-wave cascade voltage multiplier operating at about $90 \mathrm{kHz}$. A stack of 10 decks will be topped by the 
2160 ft 3 terminal house. This arrangement results in a very compact structure. The support structure will be four 14" O.D. vertical support columns of filament wound fiberglass-epoy tubes $10.75 \mathrm{ft}$. long. Each deck of the CW consists of two $200 \mathrm{kV}$ PIV silicon rectifier modules, two $100 \mathrm{kV} .025 \mathrm{kfd}$ capacitors and surge limiting resistors. Spark gaps protect the components from excessive voltage during surge conditions: Ten decks, each rated to $100 \mathrm{kV}$ are stacked to a height of ten feet, and the maximum gradient along the components of the power supply is $11 \mathrm{kV} / \mathrm{inch}$.

The $90 \mathrm{kHz}$ power is generated by two 4CW25, 000 tetrodes operating class $C$ into a resonator supplying the bottom end of the $\mathrm{CW}$ stack. Two regulation loops are provided: a slow one through a generating voltmeter and a fast one through a capacitative pick-off on the wall of the preinjector house. The power supply will provide a 10 ma average current with a maximum ripple of 500 volts. The load induced droop at $10 \mathrm{ma}$ is about $3 \mathrm{kV}$ which will be corrected by the drive to the $90 \mathrm{kV}$ supply. No bouncer as such is used. The response time of the fast feedback system and the high frequency of the CW excitation provide adequate correction response time.

A CW power supply essentially identical to this one was recently put into successful operation at the SuperHILAC and has provided satisfactory service.

\section{Wideröe Accelerator}

The principle requirement of the injector system accelerator is to accelerate $\mathrm{U}^{5+}$ from a kinetic energy of 15.8 to $113 \mathrm{keV} / \mathrm{amu}$. The Wideröe accelerator operates at $23.4 \mathrm{MHz}$ and has a $\pi-3 \pi$ drift tube arrangement with magnetic focussing quadrupoles in the even (long) drift tubes. The 5 meter long coaxial structure is supported by three stub lines which also control the resonant frequency and voltage distribution in the 34 drift tube gaps.

The tank will be fabricated from 0.5 inch $10 \%$ copper clad mild steel plate by a rolling and welding operation. Sealing between the tank and the end walls will be by 0-rings and copper r.f. gaskets. At full gradient, the gap voltage varies along the structure from 100 to $250 \mathrm{kV}$, with a total peak power dissipation of $75 \mathrm{~kW}$.

\section{IIIa RF Power Amplifier}

We will use an Eimac 4CW100,000 running Class $\mathrm{AB}_{2}$ in the final amplifier stage. This tube can deliver over $200 \mathrm{~kW}$ in this mode giving us ample reserve to supply resonator losses and an expected $20-40 \mathrm{~kW}$ of beam loading. Running at $30 \%$ duty factor, we will have ample plate dissipation even when supplying reactive power to the beam load. In normal operation we will run at reduced filament voltage to extend tube life. It has been our experience that with the filament voltage reduced to about $90 \%$ of its rated value we can expect over 50,000 hours ( $5-7$ years) of life on these tubes.

2. W. R. Baker et.al., Proceedings of the Symposium on Ion sources and Formation of Ion Beams, BNL Conference Report, 1971

3. E. Zajec et.al., Operation of a High-Current Xenon Source, Paper B-18, this conference.
As in the design used successfully at the SuperHILAC, the final amplifier will be tightly coupled to the accelerating structure using a loop in one of the stub lines. The voltage equation for the coupling loop is

$$
j \omega L I_{L}+j \omega H A=V_{L}
$$

The second term is the voltage induced in the loop by the cavity field. This voltage is in phase with the input voltage, $\mathrm{V}_{\mathrm{L}}$, and accounts for the real power transfer to the resonator. The first term represents the voltage drop due to loop selfinductance. When coupling to Alverez type linac cavities at the SuperHILAC this term is reduced to zero by adding a capacitive reactance to tune in out.

In an Alvarez type linac cavity the magnetic field at the wall is high enough so a reasonable size loop will give an induced voltage adequate for matching to high power $\mathrm{r}$.f. tubes, about $15 \mathrm{kV}$, so there is no need for a matching network between the tube plate circuit and coupling 10op. For the Wideröe structure the field at the stub line wall is much lower, and the dimensions are smaller. A reasonable coupling loop size gives an induced voltage of about $4 \mathrm{kV}$. Because this voltage is so low a simple matching network will be added between the 4CW100,000 and the coupling loop to increase the voltage by a factor of four. This will be done by adding an inductance in series with the coupling loop and adjusting it in conjunction with the 4CW100,000 output capacity for the proper step-up ratio. Figure 1 shows the equivalent circuit matching the plate impedance to the drive loop.

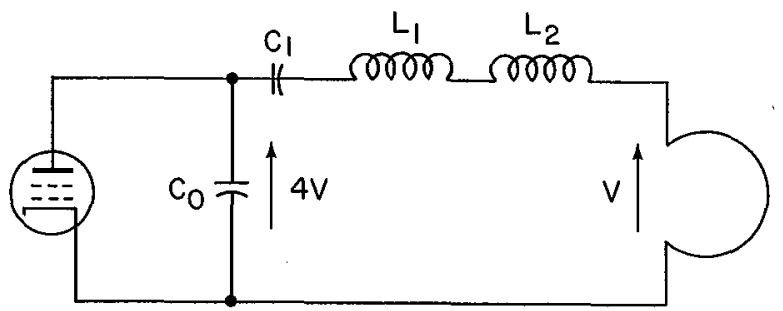

XBL $\quad 793-736$

Fig. 1

The final amplifier and its driver will be built into an enclosure that is mounted directly on the side of the stub line of the Wideröe. The final amplifier has no plate resonator as such, just a decoupling choke for the $\mathrm{B}+$ supply line. The r.f. to the driver stage will be derived from a solid-state 10 watt amplifier module located remotely.

\section{IIIb. Tape-Wound Drift Tube Quadrupoles}

The sixteen long drift tubes in the accelerator contain magnetic quadrupoles arranged in four groups. The integrated gradient-length product for all of them is 97.5 kgauss with the clear aperture diameter increasing from $1.6 \mathrm{~cm}$ for the first five units to $3.0 \mathrm{~cm}$ for the last seven. The most difficult quadrupole is the first with an effective length of $7.84 \mathrm{~cm}$ and a gradient of $12.44 \mathrm{kG} / \mathrm{cm}$. We have build and successfully tested two versions of this device. 
The construction techniques for tape-wound magnets have been published previously ${ }^{4}$. In this application, the requirements of high gradient in a short effective length were met by using pole tips $7.16 \mathrm{~cm}$ long and tapered made of vanadium perandur, contained in a yoke whose outer diameter is $20 \mathrm{~cm}$. The coil is wound with 28 turns of $0.5 \mathrm{~mm}$ thick copper tape and the measured efficiency at full field is $85 \%$, the electrical requirements being 13.6 volts at 169 amperes.

The drift tube surfaces and magnet coil are flood cooled by Freon $\mathrm{TF}-113$ at a flow rate of 3-5 gpm. The drift tube is supported from below by a single stem (inverted configuration) and the coolant return is from a aperture at the top (opposite the stem) so a gas bubble will not form and be trapped. The total weight of the drift tube assembly is $20 \mathrm{~kg}$.

Figure 2 shows the completed prototype quadrupole. Sensing loops are shown placed around the pole base, pole tip and return yoke to monitor flux in those regions as a function of excitation.

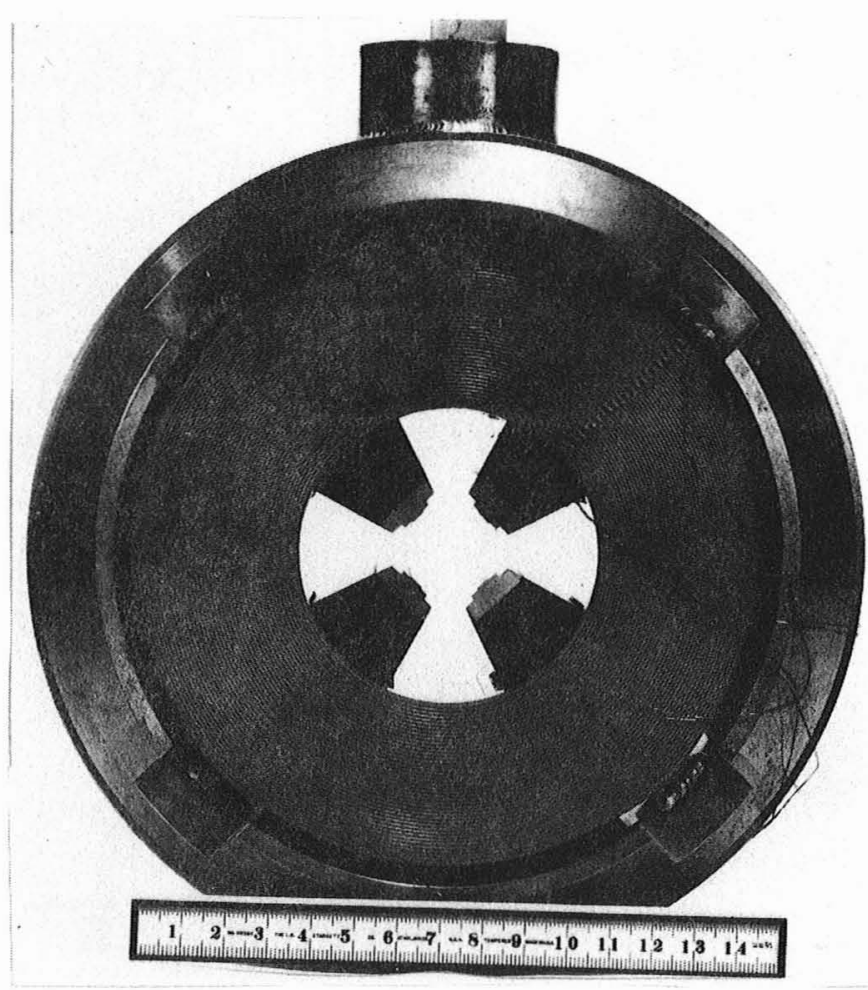

Fig. 2

IV. Matching, Stripping and Control

The beam is stripped immediately following the Wideröe and transported 12.5 meters to the entrance of the SuperHILAC. A vertical translation is included. At the SuperHILAC entrance, a fast switching magnet selects one of three possible injectors in any arbitrary 36 pulse per second sequence. The SuperHILAC itself and the beam switchyard presently have this fast beam multiplexing facility, providing at present two ion species. No debunching-rebunching will take place in the near future. Therefore about a $50 \%$ transfer efficiency of the selected charge state from the stripper to the SuperHILAC r.f. bucket is expected. When bucket matching is later introduced, the energy stability of the Wideröe must be held to $2 \cdot 10^{-4}$.

\section{IVa. Fluorocarbon Stripper}

The stripper following the Wideröe raises the mean charge state of the beam so that acceleration can continue in the first tank of the SuperHILAC. The beam is analyzed in the transport line following the stripper to select the charge state required. The stripper material is a fluorocarbon vapor of high molecular weight at a pressure of about 1 Torr evaporated from a reservoir of liquid. This type of stripper imposes no limit on the beam power and is a low maintenance item. In addition, Fomblin cracks into lighter fragments in the presence of beam which are easily swept from the stripping area.

The vapor stripper will consist of a reservoir of Fomblin Y-Vac-25/9 liquid electrically heated to no more than $200^{\circ} \mathrm{C}$ by a resistance heater. At the top of the reservoir a water cooled surface thermally isolated from the reservoir will condense the vapor back into the heated bath.

The aperture diameter of the stripper is 1 cm. A cooled beam scraper will be located upstream of the stripper to protect it from missteered beam or halo.

The stripping characteristics of this material have recently been measured with the above desired stripper at LBL by Alonso and Leemann 5 for $\mathrm{Kr}, \mathrm{Xe}, \mathrm{Ho}$ and $\mathrm{Pb}$. The stripped beam shows a high asymmetry of the final charge state distribution, probably due to the long chainlike nature of the molecule. The mean charge state at a beam energy of $113 \mathrm{keV} / \mathrm{amu}$ lies between that for gas and solid strippers, but the skew toward the high charge states with Fomblin provides substantial fluxes of the charge states of interest. For a q/A of greater than .046 , that needed by the SuperHILAC, $11.5 \%$ of $\mathrm{Pb}^{10+}$ is available, rising to $14.5 \%$ of $\mathrm{Ho}^{8+}, 17 \%$ of $\mathrm{Xe}^{9+}$ and $21 \%$ of $\mathrm{Kr}^{6+}$, the percentages normalized by particle count. The corresponding numbers for a thin carbon foil stripper run between $17 \%$ to $25 \%$. However, the equilibrium thickness for carbon is less than $l \mu \mathrm{g}$ and the power limit is low. The small angle scattering in Fomblin is significantally lower than that for a foil stripper. Figure 3 shows these charge state distributions.

4. R. M. Main and Ron Yourd, Edge Cooled Tape Magnet Coils for High Current Density Application, Forth International Conference on Magnet Technology, BNL (1972)

5. J. R. Alonso and B. T. Leemann, Fluorocarbon Stripping Stripping of Low Heavy Ions, Paper D-4, this Conference.
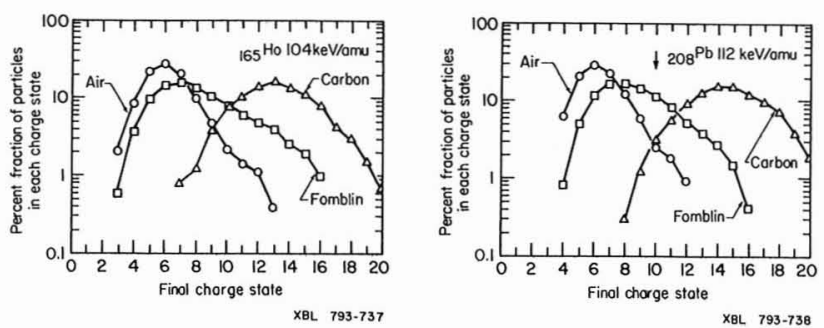

Fig. 3 
This report was done with support from the Department of Energy. Any conclusions or opinions expressed in this report represent solely those of the author(s) and not necessarily those of The Regents of the University of California, the Lawrence Berkeley Laboratory or the Department of Energy.

Reference to a company or product name does not imply approval or recommendation of the product by the University of California or the U.S. Department of Energy to the exclusion of others that may be suitable. 


$$
\text { n... }
$$

TECHNICAL INFORMATION DEPARTMENT

LAWRENCE BERKELEY LABORATORY

UNIVERSITY OF CALIFORNIA

BERKELEY, CALIFORNIA 94720 